\title{
When there seem to be no predetermining factors: Early child and proximal family risk predicting externalizing behavior in young children incurring no distal family risk
}

\author{
I. Roskam*, J.-C. Meunier, M. Stievenart, M.-P. Noël \\ Psychological Sciences Research Institute, University of Louvain, 10, Place du Cardinal Mercier, 1348 Louvain-la-Neuve, Belgium
}

\section{A R T I C L E I N F O}

\section{Article history:}

Received 23 August 2012

Received in revised form 3 October 2012

Accepted 3 October 2012

Available online 1 November 2012

\section{Keywords:}

Inhibition

Personality

Parenting

Attachment

Cumulative risk

Externalizing behavior

\begin{abstract}
A B S T R A C T
The main objective of the current study was to examine the impact of two child risk factors, i.e. personality and inhibition, and two proximal family risk factors, i.e. parenting and attachment, and the impact of their cumulative effect on later externalizing behavior among young children incurring no distal family risk. Data were collected in a longitudinal two-wave design from 161 non-referred and referred children aged three to five years at the onset of the study. All of the children were raised in families of middle to high socioeconomic status, i.e. their parents were educated to a middle to high level, had access to the job market and lived together as couples. The four risk domains were assessed at the onset of the study, while EB was rated both at the onset of the study and in the 24-month follow-up. Results confirmed that the four risk domains were each both correlates of EB and efficient at discriminating non-referred from referred children; that their combination regardless of their content (cumulative risk) provided a strong prediction of both later EB and non-referred vs referred sample membership. The results are discussed both for research and clinical purposes.
\end{abstract}

(c) 2012 Elsevier Ltd. All rights reserved.

Externalizing behavior (EB) is characterized by agitation, opposition, aggression, provocation, negative thoughts and transgression of social norms (Achenbach \& Rescorla, 2000). A certain level of EB is considered to be typical in preschoolers (Wakschlag et al., 2007). But persistent high levels of EB were found in subgroups of children (e.g. Calkins, Blandon, Williford, \& Keane, 2007). Research has tried to identify risk factors that potentially increase the likelihood of EB. Based on the work of key leaders in this topic, Loeber and Farrington (2000) established a list according to several ecological levels, i.e. child, family, school, peer and neighborhood factors. The relations between child and family factors and EB have especially been documented in young children, while the potential contribution of school, peer and neighborhood factors was more specific in the prediction of school age children's and adolescents' EB. The current research examines the impact of two single risk factors at the child level, i.e. personality and inhibition capacities, and two single risk factors at the family level, i.e. attachment and parenting, and the impact of their cumulative effect on young children's EB incurring no distal family risk. We first review studies documenting the relations between children's EB and each of the four risk factors at the child and family levels. Second, we document research into cumulative risk with EB as an outcome.

\footnotetext{
* Corresponding author.

E-mail address: Isabelle.roskam@uclouvain.be (I. Roskam).
} 


\section{Child risk factors}

Children's temperament and personality traits have both been considered as contributors to EB (Rothbart \& Bates, 1998). Temperament is defined as the biological roots of personality traits, so that its assessment is preferred for children over the age of three years (Kohnstamm, Halverson, Mervielde, \& Havill, 1998). In previous studies of temperament, the reactive factor of emotionality/neuroticism and the regulative process of effortful control have been shown to be involved in the pathogenesis of EB (Martel \& Nigg, 2006). The level of EB was also higher within early temperamental profiles characterized by low self-control, activity and emotionality (Gusdorf, Karreman, van Aken, Dekovic, \& van Tuijl, 2011; Janson \& Mathiesen, 2008). In previous studies of personality, low agreeableness, conscientiousness and emotional stability were also related to EB (Mervielde, De Clercq, De Fruyt, \& Van Leeuwen, 2005).

According to neuropsychological theories, another explanation of the development of EB could be a low level of executive functions such as inhibiting prepotent responses, interference control and cognitive flexibility which are necessary to regulate one's behavior, (Reader, Harris, Schuerlholz, \& Denckla, 1994). This hypothesis has been supported by a large number of studies that found a difference between children with EB and normally-developing children on measures of executive function (e.g. Brocki \& Bohlin, 2006); by longitudinal studies that found a significant prediction of later EB from early inhibition capacities (e.g. Nigg, Quamma, Greenberg, \& Kusche, 1999); by recent studies with typically-developing children where executive capabilities measured by laboratory tasks supported broad control processes enabling behavioral regulation (e.g. Espy, Sheffield, Wiebe, Caron, \& Moehr, 2011); and by studies demonstrating that inhibition capacities were positively related to socially appropriate behaviors (e.g. Rhoades, Greenberg, \& Domitrovich, 2009).

\section{Family risk factors}

Two subsets of family risk factors have been distinguished in previous studies, i.e. proximal and distal risks. The proximal risk factors relate to the quality of the parent-child relationship; the distal risk encompasses factors such as maternal education, incomes or paternal criminality (Flouri, 2008). With regard to the proximal factors, parenting and attachment are among the most documented. Parenting has mainly been appraised according to childrearing behavior conceptualized along two key dimensions: support and negative control (Aunola \& Nurmi, 2005). Support encompasses the affective nature of the parent-child relationship and refers to a variety of related behavior including warmth, acceptance, involvement, autonomy, monitoring and the establishment of guidelines. Negative control encompasses parents' efforts to control their children's behavior by means of coercion, inconsistent, conflictual and/or harsh discipline, or punishment. High coercion, harsh and inconsistent punishment and poor acceptance as well as lack of responsiveness and insufficient rewarding of positive behavior have been repeatedly identified as risk factors for developing EB (e.g. Barnett, Shanahan, Deng, Haskett, \& Cox, 2010; Lansford et al., 2011). Both insecurity and disorganization of attachment were also reported in meta-analyses as major risks for EB (Fearon, Bakermans-Kranenburtg, Van Ijzendoorn, Lapsley, \& Roisman, 2010; Van Ijzendoorn, Schuengel, \& Bakermans-Kranenburg, 1999). Disorganized and insecure children seemed to lack attachment strategies to be able to cope with stress in difficult situations, using the caregiver as a source of comfort. For Stacks (2007), insecurity, in particular ambivalence was associated with the highest level of EB in preschoolers. For Smeekens, Riksen-Walraven, and van Baken (2009) however, attachment disorganization was a better predictor of the children's later socio-emotional development than security.

The distal risk factors are concerned with the broader family context of adversity, in particular low socio-economic status and its correlates such as financial distress, poor education, overcrowding, psychiatric status of the parents, lack of access to social support, and teen or single parents (e.g. Bendersky, Bennett, \& Lewis, 2006; Sameroff, Seifer, \& McDonough, 2004; Trentacosta et al., 2008). Distal risk factors were demonstrated to be strong correlates of EB (e.g. Lanza, Rhoades, Nix, \& Greenberg, 2010; Schonberg \& Shaw, 2007). EB was found to be much more common among children reared in high contextual risk families (Lansford et al., 2006). However, not all children displaying EB come from these families. Pathological levels of EB also occur in the absence of evident contextual stressors among children who were not predestined by their developmental setting to display EB. While several studies have been conducted in community samples with a certain portion of their samples characterized by limited to no distal risk, few if any studies have examined samples especially selected on the basis of limited to no distal stress. The rationale for considering such samples is both to find out what child and proximal family factors explain variations in EB and to confirm the cumulative hypothesis in the absence of contextual stressors that usually account for a great amount of variance in EB.

\section{The accumulation of risk factors}

The empirical studies that have been reviewed above have considered each child and family risk factor in isolation. Multiple risk studies are scarcer, but they address the importance of considering several frameworks in combination. One of the most interesting hypotheses coming from the multiple risk studies is the cumulative principle, which posits that the accumulation of risk factors, even regardless of their content, influences behavioral outcomes: the higher the number of risk factors, the higher the EB level (Cicchetti \& Rogosch, 1996). Several studies have demonstrated a linear relation between the cumulative risk index, computed by summing the number of dichotomized risk factors, and children's EB (e.g. Appleyard, Egeland, van Dulmen, \& Sroufe, 2005; Furniss, Beyer, \& Müller, 2009; Greenberg, Speltz, DeKlyen, \& Jones, 2001). The 
literature review revealed significant variations in the risk factors under consideration, in the number of factors, which ranged from 5 (e.g. Appleyard et al., 2005) to 20 (e.g. Deater-Deckard, Dodge, Bates, \& Pettit, 1998), and in the way that they were treated. Thus some studies used a single index which including both proximal and distal family risk factors (e.g. Lanza et al., 2010), or which only included distal risk factors (Trentacosta et al., 2008); others used several sub-indexes according to different ecological levels, i.e. a child sub-index with factors such as gender, temperament or medical complications, a sociocultural sub-index with factors such as income, marital status, teenage pregnancy or life events, and a parenting sub-index with factors such as non-maternal care, father's involvement, parental conflict and exposure to violence (e.g. Deater-Deckard et al., 1998; Greenberg et al., 2001). Other variations come from the sample characteristics. Some studies have been conducted with families which are subject to distal risk, such as low-income families (e.g. Appleyard et al., 2005; Ezpeleta, Granero, de la Osa, \& Domènech, 2008; Kerr, Black, \& Krishnakumar, 2000; Trentacosta et al., 2008), or adolescent mothers (e.g. Keller, Spicker, \& Gilchrist, 2005), while others have used referred samples (e.g. Greenberg et al., 2001) or community samples (e.g. Deater-Deckard et al., 1998; Furniss et al., 2009; Gerard \& Buehler, 2004; Lanza et al., 2010; Rouse, Fantuzzo, \& Leboeuf, 2011). Regardless of these variations, all of the studies supported the cumulative risk hypothesis.

\section{The current study}

The current study examines the predictive influence of both child risk factors, i.e. those relating to personality and inhibition capacities, and proximal family risk factors, i.e. those relating to parenting and attachment, on children's EB two years later in a sample characterized by the absence of distal family risk. To the best of our knowledge, no study has up to now combined the framework of executive functioning with that of personality, parenting or attachment in order to explain young children's EB. These child and proximal family factors were first verified to be effective correlates of children's EB. EB was expected to be related to difficult personality traits (e.g. Mervielde et al., 2005), low inhibition capacities (e.g. Espy et al., 2011), negative parenting (e.g. Barnett et al., 2010), and insecure and disorganized attachment (e.g. Fearon et al., 2010). The child and family risk factors were also expected to discriminate children referred for pathological levels of EB from non-referred children (e.g. Brocki \& Bohlin, 2006; Greenberg et al., 2001). Second, the current study aims to test the cumulative principle with respect to child and proximal family factors (Cicchetti \& Rogosch, 1996; Rutter, 1979). Children displaying higher levels of EB should be characterized by a higher number of risk factors, regardless of their content, than children displaying lower levels of EB. In other words, an increase in the number of high-risk domains at the onset of the study should be associated with an increased probability of later EB. The number of risk factors is also expected to discriminate the children referred for pathological levels of EB from the non-referred children (Greenberg et al., 2001; Lanza et al., 2010).

\section{Method}

\subsection{Sample}

This study was part of the longitudinal H2M (Hard-to-Manage) Children research program conducted at the Psychological Sciences Research Institute of the University of Louvain (Belgium) with the collaboration of the Saint Luc University Clinic in Brussels (Belgium). Data were collected from a sample of 95 non-referred (59\%) and 66 referred (41\%) three-to-five-year-old children. The non-referred subsample was recruited when the children were in the first to third kindergarten years in middle-to-high socio-economic status elementary schools in the French-speaking part of Belgium. ${ }^{1}$ The referred subsample was recruited from pediatric units in the Saint Luc University Clinic in Brussels where the parents had referred their child for pathological EB problems (arousal, opposition, agitation, aggressiveness, non-compliance).

Additional inclusion and exclusion criteria were defined in the two sub-samples in order to select children incurring no distal family risk. The criteria considered were relevant to the cultural and economical context of Belgium, i.e. educational level and marital and employment status (Colicis et al., 2004; Oakes \& Rossi, 2003). To be included in our sample, both the mother and the father had to have completed at least secondary school, as this is necessary to gain access to the job market in Belgium (Colicis et al., 2004). The educational level of the parents was taken to be the number of years of education they had completed, counting from first grade onward. None had completed fewer than 12 years. Some had completed 12 years, corresponding to the end of secondary school and to compulsory education in Belgium; others had completed three more years (corresponding to undergraduate studies); others had gained a four-year degree or more. To be included in the sample, the parents also had to be living together or to live as a couple with another partner, because single-parent families are at risk of financial distress. Moreover, at least one of the two parents had to be in full-time employment. Note that no data were collected about family incomes. This measure is first culturally unacceptable to the parents (Lorenzi-Cioldi, 2003; Peterson, 2000). Second, family incomes are highly correlated to educational level in Belgium (Oakes \& Rossi, 2003). Due to the current economical context in the country, educational level is preferred as a stable indicator rather than the family incomes that fluctuate. The socio-demographic characteristics of the two subsamples are presented in Table 1 and are very similar for the

\footnotetext{
${ }^{1}$ Official indicators of the socio-economical status of schools are provided by the Belgian Statistical Service ETNIC, see http://www.enseignement.be/ index.php?page $=0$ \&navi $=2264$.
} 
Table 1

Socio-demographic characteristics of the two subsamples and related Belgian national statistics.

\begin{tabular}{|c|c|c|c|}
\hline & Non-referred, $N=95$ & Referred, $N=66$ & $\begin{array}{l}\text { Belgian national } \\
\text { statistics }^{\mathrm{a}}\end{array}$ \\
\hline Age range in months (mean-standard deviation) & $36-71(54.72-9.37)$ & $33-71(50.71-11.50)$ & - \\
\hline Nos. of children by age $(3 / 4 / 5)$ at $\mathrm{T} 1$ & $25 / 38 / 32$ & $28 / 21 / 17$ & - \\
\hline Gender (\% girls) & $51 \%$ & $27 \%$ & - \\
\hline Mothers' educational level (secondary/undergraduate + graduate) & $19 \% /(52+29)=81 \%$ & $23 \% /(55+22)=77 \%$ & $74.6 \% / 25.4 \%$ \\
\hline Fathers' educational level (secondary/undergraduate + graduate) & $29 \% /(52+19)=71 \%$ & $30 \% /(53+17)=70 \%$ & $73.6 \% / 26.4 \%$ \\
\hline Marital status (\% living together) & $89 \%$ & $82 \%$ & $65 \%$ \\
\hline Mothers' employment (\% workers) & $85 \%$ & $87 \%$ & $56 \%$ \\
\hline Fathers' employment (\% workers) & $91 \%$ & $87 \%$ & $70 \%$ \\
\hline
\end{tabular}

a Source: National Institute of Statistics (INS) of Belgium, data from the year 2005.

two subsamples with the exception of gender composition: girls were under-represented in the referred sample. Table 1 also presents the Belgian national statistics provided by the National Institute of Statistics in Belgium (INS ${ }^{2}$ ) about the educational level of Belgian people aged 25 years or over, the national number of couples living together with their child(ren), and the rate of employment among Belgians aged 25-49 years. Comparison with these statistics suggests that the sample may be considered to be characterized by the absence of evident distal family risk.

Furthermore, inclusion and exclusion criteria were added in the referred group in order to select children whose EB was the core mental health problem. We therefore excluded children with overall developmental delay or intellectual disability. This applied to children born prematurely (before 37 weeks), autism, dysphasia or substantial language delay according to an examination by a speech therapist (for more details see also Van Schendel, Schelstraete, \& Roskam, in press) or IQ below 80 tested using the WPPSI-III (Wechsler, 2004) (for more details see also Stievenart, Roskam, Meunier, \& Van de Moortele, 2010). All of the referred children attended normal school.

In the French-speaking part of Belgium, middle-class parents who are worried about their young child's behavior usually seek advice from a pediatrician who checks for a possible neurological or biological origin of the problem, for instance epilepsy or allergy. If no medical cause is found by the pediatrician, a psychological origin of the problems is suspected, but neither diagnosis nor treatment is provided before the age of 7 . When the child is seven years old, if the behavioral problems persist, a multidisciplinary assessment combining language, executive functions and socio-emotional assessment is carried out. This can lead to a diagnosis such as attention deficit and/or hyperactivity disorder, and in turn to a drug and/or therapy treatment. This way of treating referrals for EB is a matter of Belgian policy in the French-speaking part of Belgium: children as young as four-year-old can be referred for behavioral problems to a pediatrician or to mental health services but in absence of neurological or biological origin of the problem, neither diagnosis nor systematic treatment is provided under the age of seven. In this context, the referred children in our sample had not undergone any systematic treatments between the two waves of assessment, although a few of them (9\%) had taken part in psychomotor activities conducted by physiotherapists. The frequency of such activities and their relation to EB and its correlates were explored and found not to have any significant effect on the variables under consideration. The effect of these activities as a variable was therefore dropped in subsequent analyses.

\subsection{Procedure}

The parents were informed about the longitudinal research program. They were also told that the data would remain confidential. Informed consent was obtained. The data presented here come from two assessment waves: at the outset of the research program (T1) and at the 24-month follow-up (T2).

Twelve fourth-year master's students and three research assistants in the Department of Psychology at the University of Louvain (UCL), who had been intensively trained in sampling and data collection procedures, undertook the data collection. At T1, both parents were instructed to complete three separate questionnaires. The first related to their child's personality traits and was completed by the parents together. The second and the third were completed by the parents independently without consulting one another. They assessed their child's EB and their parenting behavior toward the target child respectively. The set of questionnaires was given by the preschool teachers to the parents of non-referred children and by the research assistants to the parents of referred children. The parents had to complete them at home within the following two weeks. At T1, children were also visited at school. The children were each examined in a quiet room. The children completed an assessment tool designed to assess children's attachment representations (Bretherton, Ridgeway, \& Cassidy, 1990) and were also exposed to six inhibition tasks. At T2, both parents were asked to complete the questionnaire relating to their child's EB.

As is customary in longitudinal research, attrition occurred. Among the 414 children (30\% referred) who were enrolled in the research program, some had incomplete data: for example, the father's questionnaire about the child's EB was missing at

\footnotetext{
2 http://statbel.fgov.be/fr/statistiques/chiffres/.
} 
T1 or there was incomplete administration of the inhibition tasks because the child was ill at the moment of the school visit. In order to test the cumulative risk principle, only the data that had been fully completed both for EB at T1 and T2, and for all the risk factors at T1, were considered. This was the case for 161 children (43\% referred). A full response rate of $40 \%$ was good, considering that the multi-task longitudinal design was regarded as time-consuming for the families involved. Analysis of attrition by comparing children who dropped out or who had incomplete data, and children who fully completed the two waves of data collection revealed no systematic significant differences either in the socio-demographic variables, i.e. child's age and gender, and parents' educational level, marital and employment status, or in T1 measures of EB, personality, inhibition, parenting and attachment.

\subsection{Outcome measure}

Child externalizing behavior (EB) was assessed independently at T1 and at T2 by the two parents, who had to complete the four subscales (angry, aggressive, egotistical and oppositional behavior) of the Profil Socio-Affectif (PSA, Dumas, LaFrenière, Capuano, \& Durning, 1997) relating to EB. It provides six-point Likert-type scales under each item, ranging from "almost never occurs" to "almost always occurs". Items scoring high on the EB scale include, for example, "takes pleasure in harming others". The French adaptation of the scale was validated on a sample of 800 preschoolers ( 387 girls, 413 boys) aged from 30 to 78 months, and demonstrated good properties (Dumas et al., 1997). At T1, all of the children were aged from 30 to 78 months old. In order to make the longitudinal analysis possible, the PSA was also administered at T2, where $47.8 \%$ of the sample was older than 78 months. We therefore verified the internal consistency of the EB scale that was considered here for the analyses. Cronbach's alphas were .86 at T1 and .89 at T2, ensuring good reliability of the measure in the longitudinal collection of data. A single EB variable was computed by averaging the mother's and the father's EB score $(r=.68$ at T1 and $r=.69$ at T2). Data were checked for normality. The test for normality was significant with respectively Kolmogorov-Smirnov $(K S)(161)=.09, p<.01$ and $K S(161)=.07, p<.05$, for EB at T1 and at T2. The scoring of the PSA is such that a higher score on the scale corresponds to a higher level of behavioral adjustment, in other words to a lower level of EB. For the readability of the results, we recoded the PSA score so that higher scores indicate higher EB.

\subsection{Measures of child risk factors}

Child personality was assessed at T1 by the two parents together, who completed the Bipolar Rating Scales based on the Big Five model (EBMCF, Roskam, de Maere-Gaudissart, \& Vandenplas-Holper, 2000). This includes 25 items, five for each of the five factors: Extraversion, Agreeableness, Conscientiousness, Emotional Stability and Openness. A nine-point Likert-type scale is provided under each item, with higher results indicating better adjustment. Items that are high on the Extraversion scale include, for example, "shy-confident", and on the Emotional stability scale, for example, "nervous-calm". The model was validated on a sample of 1196 mothers of non-referred children aged three to nine years. Cronbach's alpha varied from .67 to .90 , test-retest correlations over a one-week period varied between .80 and .89 , and the total amount of variance explained by the factors was $60.5 \%$ (Roskam et al., 2000). The correlations that were computed for the 161 participants in the current study showed that the five factors were related to each other with coefficients ranging from .29, $p<.001$ (between agreeableness and conscientiousness) to .50, $p<.001$ (between emotional stability and conscientiousness). In order to reduce the number of predictors in the analyses, a principal component factor analysis was conducted with the five scores. Both the sample size and the moderate correlations between the five scores were considered to be sufficient to perform a factor analysis following the guidelines proposed by Floyd and Widaman (1995). A single factor, "personality", was produced which explained $44 \%$ of the variance, with factor loadings ranging from .48 to .79 and with a Cronbach's alpha of .65. The factorial scores were used in the analyses. A high score indicated adaptive personality traits while a low score indicated difficult personality. Data were checked for normality. The test for normality was significant with $K S(161)=.08, p<.01$.

Inhibition was assessed with six tasks that were completed by children at the onset of the study. In the first five tasks, there was a control condition in which no inhibition was involved and a test condition that required the inhibition of a dominant response. In the three blobs task (based on Balamore \& Wozniack, 1984), the child had to tap with a hammer on three colored spots in succession: first the one on the left, then the one in the middle and then the one at the right end (ten times in a row). In the test condition, the child was asked to tap each spot one at a time but in an unusual direction: left, right and then middle. In Luria's handgame (see Diamond \& Taylor, 1996) the child had to mimic the examiner's action in the test condition (taps once or twice on the table) but do the opposite of the examiner's action in the test condition. In the card sorting test (based on Brooks, Hanauer, Padowska, \& Rosman, 2003), the child had to place rabbit cards on the rabbit model card and truck cards on the truck model card in the control condition, and the opposite in the test condition. In both conditions, the first eight cards varied only on the dimension of the shape (rabbit or truck), but the last eight ones also varied on the color dimension (blue or yellow). In cat, dog and fish (inspired by the day-night task, from Gerstadt, Hong \& Diamond, 1994), the child sees series of drawings of cats, dogs and fishes and has to name each drawing as fast as he/she can in the control condition. In the test condition, the child is required to say "cat" when he/she sees a dog, "dog" when he/she sees a cat and "fish" when he/she sees a fish. In the monsters Stroop (developed by S. Censabella and M.P. Noël, unpublished), rows of drawings of monsters with different colors were presented to the child who had to name the color of each monster (control condition). In the test 1 condition, each monster was placed on a different colored background square and the child had to name the color of the monster, avoiding distraction from the color of the background. In the test 2 condition, the instructions 
were the same except that if the monster is upside-down, the child had to say the color of the background. Finally, we used the statue test (NEPSY, Kemp, Kirk, \& Korkman, 2001) in which the child is asked to maintain a body position with eyes closed without talking during a 75-s period and to inhibit the impulse to respond to sound distractors. A principal component factorial analysis was conducted on the six tasks' error scores. Both the sample size and the moderate correlations between the six tasks (ranging from $r=.26$ and $r=.44$ ) were considered to be sufficient to perform a factor analysis following the guidelines proposed by Floyd and Widaman (1995). A single factor, "inhibition", was produced which explained $47 \%$ of the variance, with factorial loadings ranging from .62 to .76 and with a Cronbach's alpha of .74. The factorial scores were used for the analyses. Data were checked for normality. The test for normality was significant with $K S(161)=.09, p<.01$.

\subsection{Measures of proximal family risk factors}

\subsubsection{Parenting}

Parenting behavior was assessed at T1 by the mothers and the fathers separately, with the preschoolers' form of the Evaluation des pratiques éducatives parentales-Preschool and primary school form designed for parents of two-to-seven-yearold children (EPEP-PPSF, Meunier \& Roskam, 2009). The EPEP-PPSF is a 40-item instrument yielding nine factors: Positive Parenting, Monitoring, Rules, Discipline, Inconsistent Discipline, Harsh Punishment, Ignoring, Material Rewarding, and Autonomy. A five-point Likert-type scale is provided for each item, ranging from "never" to "always". This instrument has been validated on 565 French-speaking mothers and fathers of children developing normally and shows good psychometric properties (Meunier \& Roskam, 2009). For the nine-factor solution extracted in the validation study, Cronbach's alpha ranged from .59 to .90; the total percentage of variance explained was $61.36 \%$. Confirmatory factor analyses from the validation study showed that two second-order factors covering the supportive and controlling dimensions of parenting emerged from the initial factor solution. The supportive factor was composed of Positive Parenting, Autonomy, and Rules and included items such as "When my child seems to have a problem, I discuss with him/her what is wrong". The controlling factor included Discipline, Harsh Punishment, and Ignoring and included items such as "When my child does something that is not allowed, I only talk to him/her again when he/she behaves better". The fit measures in the validation study demonstrated an acceptable fit to the data, with $C F I=0.94$, RMR =0.03, and RMSEA = 0.05 (Hu \& Bentler, 1999; Meunier \& Roskam, 2009). Similarly to Meunier, Roskam, Stievenart, et al.'s study (2011) and in order to limit the number of predictors in the analyses, a support-to-negative-control ratio was calculated in the current research both for the mothers and the fathers. A score of 1 thus indicates equal amounts of support and negative control, whereas a score of less than 1 indicates more negative control than support, and a score of greater than 1 indicates more support than control. While the risk that was associated with parenting was mostly appraised in previous studies from the perspective of the mothers, in the current study it was assessed considering both the mothers' and the fathers' ratios. More than $80 \%$ of the families in the sample were hence two-parent families; in families where parents were separated, both the mother and the father were involved in childrearing. A single factor, "parenting", was computed by averaging the mother's and the father's support-to-negative-control ratio $(r=.61)$. Data were checked for normality. The test for normality was significant with $K S(161)=.07, p<.05$.

\subsubsection{Attachment}

Taken from the MacArthur Story Stem Battery (Bretherton \& Oppenheim, 2003), the French version of the Attachment Story Completion Task (ASCT) as designed for children from three to seven years of age was used to assess the children's attachment representations (Bretherton et al., 1990) at T1. The administration of the task was video-recorded. The procedure includes five story stems, for example the child is afraid (of a monster in the bedroom), or experiences a separation from and reunion with parents. The narratives were coded using the Q-set procedure, Cartes pour le Codage des Histoires à completer (CCH, Miljkovitch, Pierrehumbert, Karmaniola, \& Halfon, 2003). This procedure provides four attachment scores relating to the four usual patterns: security, inhibition, ambivalence and organization. In order to limit the number of predictors in the analyses and in line with existing studies, only the secure and the organization scores were under consideration in the current study. To maximize the coding validity, $20 \%$ of the video-recorded ASCTs were coded separately by two independent coders. The agreement between the two coders was computed using intraclass correlation and was .80, similar to that recently reported with ASCTs in a Spanish sample of 30 randomly selected cases, with a total of 10 judges (Pierrehumbert et al., 2009). Data were checked for normality. The test for normality was significant with $K S(161)=.13, p<.001$ for security and $K S(161)=.09, p<.01$ for organization.

\subsection{Statistical analyses}

The first set of analyses aimed to test whether and to what extent the four risk factors were correlates of EB, considered here as a continuum ranging from regular to pathological levels of EB. A certain overlap was seen between the two subsamples, since several non-referred children displayed a moderate to high level of EB and several referred children displayed only a moderate level. As an illustration of this overlap, the scores on the EB scale ranged from 25.75 to 68.75 $(M=52.49, \mathrm{SD}=9.18)$ and 24.62 to $73.00(M=45.27, \mathrm{SD}=11.00)$ at $\mathrm{T} 1$ and $\mathrm{T} 2$ respectively in the referred sample and from 14.00 to $68.00(M=46.15, \mathrm{SD}=10.72)$ and 9.00 to $55.00(M=29.52, \mathrm{SD}=10.06)$ at $\mathrm{T} 1$ and $\mathrm{T} 2$ respectively in the non-referred sample. As other illustration, the distribution of the two subsamples according to children's EB at T2 is displayed in Fig. 1. Since the socio-demographic characteristics of the two subsamples were very similar (see Table 1), they could be taken 


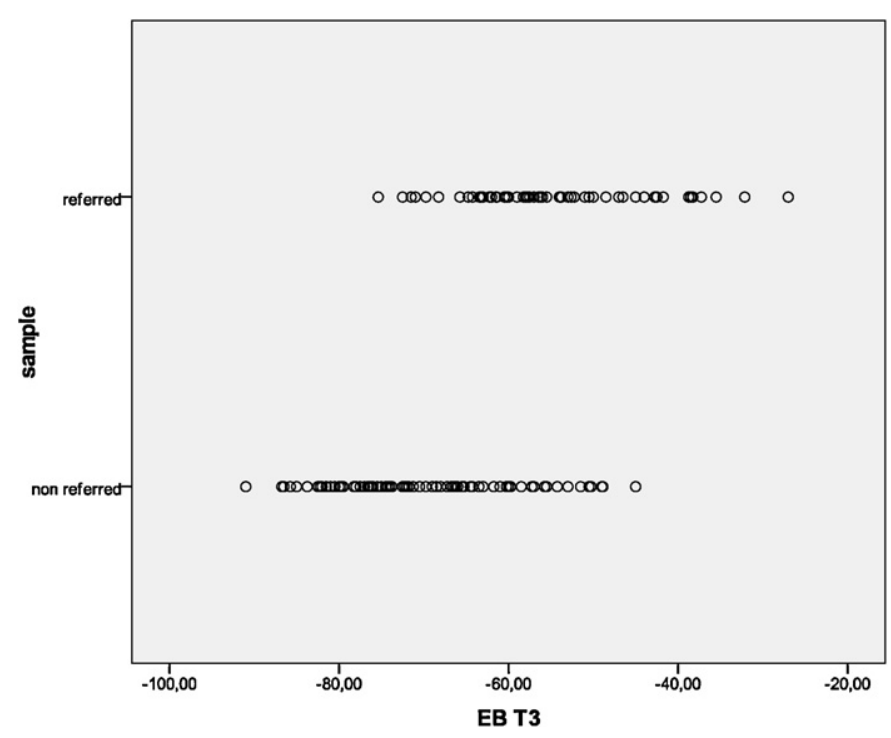

Fig. 1. The overlap between the two sub samples for EB at T2.

together to form a single sample, in which, considering both non-referred and referred children, we maximized the distribution on the continuum from regular to pathological behavior.

The four risk factors were also considered as continuous scores, and correlations were computed between these and EB at $\mathrm{T} 1$ and $\mathrm{T} 2$. The predictive power of the child and proximal family risk factors at T1 with respect to EB at T2 was appraised with a regression model where the influence of $\mathrm{EB}$ at $\mathrm{T} 1 \mathrm{on} \mathrm{EB}$ at T2, i.e. the stability of the construct, age and gender were controlled for. The discrimination between the two subsamples, i.e. referred and non-referred children, was studied by means of $t$-tests involving both the EB scores and the scores in each of the four risk factors.

The second set of analyses aimed to test the cumulative risk hypothesis. A dichotomous score, i.e. high vs low risk, was computed in each of the four risk factors. High-risk was defined as a score in the lower third (for child personality, attachment, and parenting) or upper third (for inhibition errors) of the distributions in the whole sample (referred and nonreferred). Since significant age-related effects were displayed for three of the four factors, with younger children displaying higher overall risk than older ones $(F(2 ; 155)=56.79, p<.001$, for inhibition, $F(2 ; 155)=5.80, p<.001$, for parenting, $p<.01$, $F(2 ; 155)=5.81, p<.001$, for attachment, $p<.01)$, the scores of the risk factors were first standardized in each of the three age groups (three, four and five) so that the relative position of each child remained the same in his/her age group and the age-related effect disappeared. Those who were in the target one-third of the distribution in the sample were considered as incurring the risk factor, the others as safe. A cumulative risk was finally computed for each child by adding together the dichotomous (0-1) scores in each of the factors under consideration. In this second set of analyses, the cumulative risk at T1 was considered as a predictor of EB at T2 in a linear regression where the influence of EB at T1 on EB at T2, i.e. the stability of the construct, age and gender were controlled for. Also, the allocation of the children in the referred vs the non-referred subsample according to the cumulative risk was appraised with a binary logistic regression and the Relative Improvement Over Chance index.

\section{Results}

\subsection{Correlates of $E B$}

The bivariate correlations between the EB score both at T1 and at T2 $(r=.32, p<.001)$ and the continuous scores of the child and family risk factors reveal coherent patterns of relations between risk factors which support the validity of the measures in our sample. Positive parenting was associated with adaptive personality traits $(r=.41, p<.001)$, attachment security and organization $(r=.22, p<.01$ and $.19, p<.05$ respectively), and inhibition capacities $(r=.24, p<.01)$; adaptive personality with organization $(r=.29, p<.01)$ and inhibition $(r=.30, p<.001)$; and organization with inhibition $(r=.28$, $p<.01$ ). The association between EB at T1 and the risk factors was low but significant with $r=-.14, p<.10, r=-.16, p<.05$, $r=-.18, p<.05$ for inhibition, parenting and personality respectively. The correlation was low and not significant between EB at T1 and attachment with $r=-.09, p>.10, r=-.10, p>10$ for security and organization respectively. At T2 however every factor apart from attachment security was moderately related to EB in the expected direction with $r=-.22, p<.01$, $r=-.31, p<.001, r=-.37, p<.001, r=-.60, p<.001$ for organization, inhibition, parenting and personality respectively. Since attachment security was not related to EB either at T1 or at T2, it was not considered as a risk factor in the linear regression model. 
Table 2

Regression analyses predicting EB at.

\begin{tabular}{|c|c|c|}
\hline \multirow{3}{*}{$\begin{array}{l}\text { Model 1 } \\
\Delta R^{2}=.23^{* * *}\end{array}$} & EB & $.38^{* * *}$ \\
\hline & Age & $-.27^{* * *}$ \\
\hline & Gender & $.23^{* *}$ \\
\hline \multirow{4}{*}{$\begin{array}{l}\text { Model 2a } \\
\Delta R^{2}=.24^{* * *}\end{array}$} & EB & $.29^{* * *}$ \\
\hline & Age & $-.17^{* *}$ \\
\hline & Gender & $.19^{* *}$ \\
\hline & Personality & $-.51^{* * *}$ \\
\hline \multirow{4}{*}{$\begin{array}{l}\text { Model 2b } \\
\Delta R^{2}=.03^{* *}\end{array}$} & EB & $.41^{* * *}$ \\
\hline & Age & -.08 \\
\hline & Gender & $.20^{* *}$ \\
\hline & Inhibition errors & $.26^{* * *}$ \\
\hline \multirow{4}{*}{$\begin{array}{l}\text { Model 2c } \\
\Delta R^{2}=.05^{* * *}\end{array}$} & EB & $.34^{* * *}$ \\
\hline & Age & $-.21^{* *}$ \\
\hline & Gender & $.19^{* *}$ \\
\hline & Parenting & $-.24^{* * *}$ \\
\hline \multirow{4}{*}{$\begin{array}{l}\text { Model 2d } \\
\Delta R^{2}=.03^{*}\end{array}$} & EB & $.39^{* * *}$ \\
\hline & Age & $-.24^{* *}$ \\
\hline & Gender & $.19^{* *}$ \\
\hline & Attachment organization & $-.17^{*}$ \\
\hline \multirow{5}{*}{$\begin{array}{l}\text { Model 3a } \\
\Delta R^{2}=.25^{* * *}\end{array}$} & EB & $.31^{* * *}$ \\
\hline & Age & -.07 \\
\hline & Gender & $.17^{* *}$ \\
\hline & Personality & $-.49^{* * *}$ \\
\hline & Inhibition errors & $.17^{*}$ \\
\hline \multirow{5}{*}{$\begin{array}{l}\text { Model 3b } \\
\Delta R^{2}=.07^{* * *}\end{array}$} & EB & $.35^{* * *}$ \\
\hline & Age & $-.19^{* *}$ \\
\hline & Gender & $.17^{*}$ \\
\hline & Parenting & $-.22^{* *}$ \\
\hline & Attachment organization & $-.14^{*}$ \\
\hline \multirow{7}{*}{$\begin{array}{l}\text { Model } 4 \\
\Delta R^{2}=.26^{* * *}\end{array}$} & EB & $.30^{* * *}$ \\
\hline & Age & -.06 \\
\hline & Gender & $.16^{* *}$ \\
\hline & Personality & $-.46^{* * *}$ \\
\hline & Inhibition errors & $.15^{\dagger}$ \\
\hline & Parenting & -.07 \\
\hline & Attachment organization & .02 \\
\hline
\end{tabular}

Linear regression analysis was performed where the child and proximal family risk factors predicted EB at T2. Successive models were computed. In Model 1, only EB at T1, age and gender were entered as predictors. In Models 2a, b, c, and d, the four risk factors were entered as predictors in order to establish whether and to what extent they explain a significant amount of variance over and above EB at T1, age and gender, and to evaluate their predictive power. Models 3a and b controlled for EB at T1, age and gender, and tested the child and the proximal family risk factors predicting EB at T2. Finally, Model 4 considered all the risk factors as predictors. The results are shown in Table 2. Each of the four risk factors was seen to be an independent predictor of later EB, and all of them were significant at .01 or .001 (Models 2a, b, c, d). The child factors had a higher predictive power than the proximal family risk factors, with $48 \%$ of explained variance for the child factors model (Model 3a) and 30\% for the proximal family factors model (Model 3b). Personality was the strongest correlate of EB, but in the child factors model the inhibition errors remained significant over and above the influence of child personality (Model 3a). In the last model (Model 4), only the child factors remained significant, while the proximal family factors were no longer significant. 
Table 3

Descriptive statistics and $t$-tests for EB and risk factors in the non-referred and in the referred samples.

\begin{tabular}{|c|c|c|c|}
\hline & Non-referred sample, $M(S D)$ & Referred sample, $M(S D)$ & $t$-tests \\
\hline $\mathrm{EB}$ at $\mathrm{T} 1$ & $-53.85(10.72)$ & $-47.51(9.18)$ & $-4.03^{* * *}$ \\
\hline $\mathrm{EB}$ at $\mathrm{T} 2$ & $-70.48(10.06)$ & $-54.73(11.00)$ & $-9.39^{* * *}$ \\
\hline Personality & $6.28(.75)$ & $4.95(.98)$ & $5.49^{* * *}$ \\
\hline Inhibition errors & $-.21(1.46)$ & $1.00(1.60)$ & $-4.99^{* * *}$ \\
\hline Parenting & $1.73(.34)$ & $1.56(.36)$ & $9.65^{* * *}$ \\
\hline \multicolumn{4}{|l|}{ Attachment } \\
\hline Security & $1.19(1.04)$ & $1.29(1.07)$ & -.57 \\
\hline Organization & $.83(.52)$ & $.33(.62)$ & $2.97^{* *}$ \\
\hline
\end{tabular}

$p<.01$

*** $p<.001$.

$T$-tests were then computed to verify if the risk factors discriminated the children from the referred and the non-referred groups. The results are presented in Table 3. The two subsamples were seen to differ in their mean level of EB both at T1 and $\mathrm{T} 2$, but the difference was higher at T2 than at T1. All of the risk factors discriminated the referred from the non-referred children well in the expected direction with the exception of attachment security, which was therefore not used in the subsequent analyses.

\subsection{Cumulative risk hypothesis}

The cumulative risk hypothesis was first tested by regressing the EB score at T2 on the number of risk factors at T1 regardless of their content, with the influence of EB at T1 on EB at T2, i.e. the stability of the outcome, age and gender being controlled for (with $\beta=.33, t=5.16, p<.001, \beta=-.18, t=2.73, p<.01, \beta=.13, t=1.91, p>.05$, respectively). The number of risk factors at T1 significantly predicted the EB score at T2 $(\beta=-.42, t=-6.26, p<.001)$, over and above the influence of EB at T1, age and gender (adjusted $R^{2}=.38$ ).

A logistic regression was employed to test whether the number of risk factors, regardless of their content, was a good predictor for allocating the children to the non-referred and to the referred sample. The number of risk factors significantly predicted the sample to which the children belonged ( $\equiv=39.02(.22), p<.000$ ), and had a good pseudo- $R^{2}$ (Nagelkerke's $R_{N}^{2}=.45$ ) and an odds ratio of 4.12 , meaning that for every additional risk factor the likelihood of belonging to the referred sample increased by a factor of 4.12 .

The Relative Improvement Over Chance (RIOC, Cairney \& Streiner, 2011; Copas \& Loebert, 1990) was computed as a measure of predictive efficiency. It is an index of predictive efficiency that corrects for chance and for maximum ceilings in $2 \times 2$ crosstabs. The term "RIOC" expresses the fact that knowing how much a child may incur risk factors improves case identification over chance by a certain percentage. Odds ratios were computed by dividing the odds of belonging to one of the two subsamples and incurring a given number of risk factors versus not incurring this number of risk factors by the odds of belonging to the other subsample and incurring a given number of risk factors versus not incurring this number of risk factors (Field, 2009). The results indicated that the cumulative risk was an accurate indicator. In particular, incurring no risk at all vs incurring at least one risk factor made it possible to discriminate with confidence between non-referred and referred children, resulting in non-referred being 9.44 times as likely to incur no risk with $73.64 \%$ predictive efficiency. Also, incurring two risk factors vs incurring three or four risk factors made it possible to discriminate with confidence between referred children and non-referred children, resulting in referred being 22.95 times as likely to incur three or four risk factors with $87.10 \%$ predictive efficiency.

\section{Discussion}

The main purpose of our research was to examine the impact of two child risk factors, i.e. personality and inhibition capacities, and two proximal family risk factors, i.e. parenting and attachment, as well as the impact of their cumulative effect on later EB in young children incurring no distal risk. Data were therefore gathered from typically-developing children and from children referred for pathological levels of EB. The hypotheses that were tested are that risk factors in four domains, i.e. personality, inhibition, attachment and parenting, are correlates of EB and that they discriminate non-referred children from children referred for pathological levels of EB; that an increase in the number of high-risk domains at T1 regardless of their content (cumulative risk) is associated with a high level of later EB; and that the cumulative risk contributes to the discrimination of referred from non-referred children. Most of these hypotheses were supported by the results, enabling us to draw several conclusions and make suggestions about these young children who do not seem to be predestined in any way to develop EB.

With regard to the correlates of $\mathrm{EB}$, two conclusions are prominent. First, the relations between the risk factors and EB are higher at T2 than at T1, with EB relating to difficult personality traits, low inhibition capacities, low positive parenting, and low attachment organization. At T1, the associations between these four factors and EB were low. Nevertheless, consideration of the longitudinal results shows that they appear to be higher with EB two years later. The association 
between child characteristics and proximal family factors with EB becomes more and more evident over time. Our results suggest that the four risk factors under consideration are weak correlates of the level of EB when the children are as young as three to five years, but can nevertheless discriminate referred from non-referred children well at this age, i.e., at the onset of the study. However, these four risk factors are good indicators of EB two years later. One of the core problems in developmental psychopathology is hence to identify the right interval of time between the measure of the predictors and the measure of the outcome with a view to demonstrating their causal effects. These can best be found when the measurement interval allows children sufficient time to experience significant behavior change (Jang \& Smith, 1997). The best time interval may be highly dependent on the developmental stage of the children and therefore very difficult to determine (Meunier, Roskam, \& Browne, 2011; Rueter \& Conger, 1998). Our results suggest that two years could be a relevant interval of time to appraise the impact of the early risk factors under consideration. It can also be argued that within this interval of time, negative developmental cascades (Masten et al., 2005) occurred between the risk factors, with for example negative parenting preventing inhibition capacities from progressing well. Such negative cascades could explain the important role played by the two-year interval in revealing the predictive power of the early risk factors measured at T1.

As a second conclusion with regard to the correlates of EB, only attachment organization, but not security, was seen to be negatively correlated to EB and to discriminate referred from non-referred children. This result is in line with previous findings suggesting that disorganization was a major risk for EB and a better predictor of children's later socio-emotional development than security (e.g. Green, Stanley, \& Peters, 2007; Smeekens et al., 2009). In families with low contextual risk, very low levels of security should be relatively rare. In the ASCT, security is related to the mental representation of a secure base, a core concept in attachment theory, defined as the caregiver's ability to provide a source of security to the child leading him/her to feel safe to explore the environment (Cassidy, 1999). Secure children have experienced this secure base with their principal caregivers and integrated it. Almost all children reared in low contextual risk environments have probably had such experiences to the extent that a relatively low level of security does not contribute to derailing their behavioral adaptation. The same does not seem true of organization, which was seen to contribute to derailing children's behavioral adaptation. Children who lack organized attachment strategies seemed to be unable to cope with stress in difficult situations and lacked a clear and coherent strategy for using the caregiver as a source of comfort. It was suggested that, in such cases, the parent was seen as both a source of comfort and a source of fear. Disorganized children were then faced with a dilemma: whether to approach or to withdraw from their parent. In this respect, disorganized attachment seemed to reflect fear, apprehension and confusion toward the caregiver (Green \& Goldwyn, 2002). Our results could point to the importance of emotional regulation capacities of children, in particular their ability to rely on interpersonal strategies to cope with emotions that could be partly independent of the quality of the caregiving environment. Such a conclusion provides interesting perspectives for examining additional child factors such as their emotional regulation capacities as correlates of EB.

In line with the correlations, when EB at T1, age and gender had been controlled for, personality traits, inhibition, parenting and attachment disorganization were seen to predict EB two years later. The child factors were more influential on EB at T2 than the proximal family factors, with $48 \%$ and $30 \%$ respectively of variance explained. These results are in line with the idea that high levels of deleterious environmental factors such as harsh parenting or high disorganization in attachment are relatively rare in low contextual risk families and that therefore, individual risk factors contribute more than proximal family factors to the development of later EB (Bronfenbrenner \& Ceci, 1994; Lanza et al., 2010; Schonberg \& Shaw, 2007). In line with this assumption, the influence of both parenting and attachment was no longer significant in the model where all of the child and the proximal family factors were considered as predictors. With regard to the child factors, the greatest influence came from personality traits rather than from inhibition capacities. While both of them were considered as child characteristics, it may be that children's executive functioning is actually more sensitive to environmental influences and training experiences than personality traits, which have a stronger genetic substratum (Shaffer, 2009). For this reason, the influence of personal attributes as traits is greater than that of inhibition and also than that of proximal family factors, i.e. parenting and attachment. The relation between personality traits and later EB was hence the strongest of the predictors. It could be argued that there is an overlap between the concept of personality and the concept of behavior, as both were appraised from questionnaires, but in fact the correlation between personality and EB at T1 was significant but low (.18, $p<.05)$. The relation became higher $(.60, p<.001)$ between personality at the onset of the study and EB two years later. The results therefore point to the growing importance of personal attributes in pathways leading to EB. The increasing influence of personality traits on behavioral adaptation could be understood according to the genotype-environment effects theory, which relies on three effects (passive, evocative and active) underlying the co-conspiration between hereditary and environmental contributors to mental health (Scarr \& McCartney, 1983; Shaffer, 2009). The theory proposes that the relative importance of each effect changes over the life course of development. In particular, the great importance of the passive effect early in life, i.e. environments provided by parents, steadily decreases, while the active effect becomes more important. Children become more and more active in their "niche-building interactions" according to their personal attributes or traits, which exert more and more influence on behavioral development as children mature (Shaffer, 2009, p. 83). As a main conclusion, the results overall support one of the specificities of the pathways to EB for children incurring no distal risk, i.e. that they need high individual susceptibility to derail their behavioral adaptation.

The cumulative risk, i.e. the number of risk factors at the onset of the study regardless of their content, was demonstrated to be linearly related to children's EB two years later when EB at T1, age and gender had been controlled for. It also discriminated referred from non-referred children. In particular, incurring at least three risk factors (rather than two) raises the predictive efficiency to $87 \%$. Since the cumulative principle has been demonstrated in previous research conducted with 
children from community samples and low-to-middle SES samples (e.g. Greenberg et al., 2001; Lanza et al., 2010), this principle is definitely not a specific characteristic of samples incurring no distal risk. However, combinations of at least three risk factors in the child and family domains could be one of the specificities of the pathways to EB for children reared in low contextual risk environments. Incurring three or four risk factors was hence shown to derail behavioral adaptation in such a way that almost all children are referred for pathological levels of EB. The very high predictive efficiency of these pathways has been demonstrated in a sample where only child and proximal family factors were relevant because of the absence of distal risk. A combination of three factors in the present study therefore implied factors at both ecological levels, i.e. child and family, but the predictive power of these was shown to be different. The influence of the child factors was higher than the influence of the family ones, and the deleterious level of the proximal family factors was found to be relatively low (Schonberg \& Shaw, 2007). In line with these conclusions, two preferable pathways to pathological EB could be suggested for children incurring no distal risk. Either pathological EB could result from very high susceptibility (i.e. implying at least two child risk factors, e.g. difficult personality and low inhibition capacities) activated by one environmental process (e.g. disorganized attachment or negative parenting), or it could result from high individual susceptibility (i.e. implying at least one child risk factor, e.g. difficult personality or low inhibition capacities) activated by at least two environmental processes in combination (e.g. disorganized attachment and negative parenting). In all cases, these risk factors would correspond to weakness, and not necessarily to abnormality in the clinical range.

However, these pathways to pathological EB for children reared incurring no distal risk are only preferential pathways for two reasons. First, several children incurring several risk factors had not been referred by their caregivers to a physician. As can be seen in Table 3, there was a certain overlap between the non-referred and the referred subsamples in the level of EB at T1, with several non-referred children displaying a moderate to high level of EB and several referred children displayed only a moderate level of EB. The probability of a child having been referred to a physician might, for example, depend on the caregivers' tolerance regarding the child's agitation rather than on the absolute level of EB. The other reason for considering the specific pathways to EB as only preferential is the fact that some referred children incurred no or little risk. This suggests that additional child risk factors that have not been considered in the current study need to be explored. For example, emotional regulation capacities or variation in social information processing could play a very important role in children's susceptibility to EB. Some recent theories offer other explanations of EB in children, including deficiencies in the identification and the interpretation of social cues in a social situation or in the selection of social response (e.g. Marsh \& Blair, 2008). Future studies should also explore environmental processes other than parenting and attachment that have the potential to activate personal attributes in low contextual risk families, such as sibling relationships and differential parental treatment (e.g. Meunier, Roskam, Stievenart, et al., 2011). Comparisons among environmental activators will also be necessary in order to identify those that are the most powerful with regard to child susceptibility.

In sum, the results that have been produced provide relevant information to both researchers and clinicians seeking to propose relevant assessment methods of early EB and efficient intervention focusing on young children incurring no distal risk. In a sample where the contextual risk is limited or even completely irrelevant, the assessment of the risk incurred has to be conducted at two different levels: the child and the family. At the child level, personality traits and inhibition capacities can be considered as relevant indicators of the child's susceptibility to EB, with an important role played by personality. At the family level, attachment disorganization and parenting, including both mothers and fathers, can be considered as relevant environmental activators of the child's susceptibility to EB even if their deleterious effects are not within a clinical range. Of course, other domains could also be investigated, but the results described here indicate that the four domains under consideration are sufficient in themselves to deliver a good prediction of the level of EB two years later. Assessment in each domain may lead to a dichotomous decision about the presence or the absence of a risk. The accumulation of risks, regardless of their content, can be considered as an accurate indicator, with each additional risk leading to higher EB and with special attention focusing on children incurring three risk factors or more. As a complement to the cumulative risk principle, a knowledge of the content of the risk pattern incurred by each child is important in order to reinforce intervention focusing on specific combinations of susceptibility in children and activators within their proximal environment.

While important from both clinical and research perspectives, this study has several limitations. A first important limit in studies relying on multiple related factors is the need to reduce the number of constructs in the analyses. This relates to the variables to be summarized, averaged or transformed into ratios, for example. The disadvantage is that it can be unclear precisely what is assessed by each final construct. Another limit is the number of children in the sample. Of course, a larger sample would offer many other possibilities for analysis. The time-consuming procedure that is required by studies relying on multiple related factors and including individual tasks such as those for inhibition and attachment measures, makes it difficult to consider very large samples. The risk of attrition is also especially important because of the increasing number of instruments or tasks needed for a complete assessment. In the future, attempts should be made to replicate the findings. The results obtained with young children should also be compared with those obtained with school age children and adolescents. Culturally diverse samples would also have to be considered to evaluate the specificities of pathways to EB in culturally diverse environments.

\section{Acknowledgement}

M.-P. Noël is supported by the National Research Fund of Belgium. 


\section{References}

Achenbach, T. M., \& Rescorla, L. A. (2000). Mental Health Practitioner's Guide for the Achenbach System of Empirically Based Assessment (ASEBA). Burlington: University of Vermont, Department of Psychiatry.

Appleyard, K., Egeland, B., van Dulme, M. H. M., \& Sroufe, L. A. (2005). When more is not better: The role of cumulative risk in child behaviour outcomes. Journal of Child Psychology and Psychiatry, 46(3), 235-245.

Aunola, K., \& Nurmi, J.-E. (2005). The role of parenting styles in children's problem behavior. Child Development, 76(6), 1144-1159.

Balamore, U., \& Wozniack, R. H. (1984). Speech-action coordination in young children. Developmental Psychology, 20(5), 850-858.

Barnett, M. A., Shanahan, L., Deng, M., Haskett, M. E., \& Cox, M. J. (2010). Independent and interactive contributions of parenting behaviors and beliefs in the prediction of early childhood behavior problems. Parenting: Science and Practice, 10(1), 43-59.

Bendersky, M., Bennett, D., \& Lewis, M. (2006). Aggression at age 5 as a function of prenatal exposure to cocaine, gender, and environmental risk. Journal of Pediatric Psychology, 31(1), 71-84.

Bretherton, I., \& Oppenheim, D. (2003). The MacArthur Story Stem Battery: Development, administration, reliability, validity and reflections about meaning. In R. N. Emde, D. P. Wolf, \& D. Oppenheim (Eds.), Making meaning with narratives. Oxford University Press: New York.

Bretherton, I., Ridgeway, D., \& Cassidy, J. (1990). Assessing internal working models of the attachment relationship: An attachment story completion task for 3 year-olds. (pp. 273-308)(pp. 273-308). Attachment in the preschool years: Theory, research, and intervention, Chicago, IL: University of Chicago Press.

Brocki, K., \& Bohlin, G. (2006). Developmental change in the relation between executive functions and symptoms of ADHD and co-occurring behavior problems. Infant and Child Development, 15, 19-40.

Bronfenbrenner, U., \& Ceci, S. J. (1994). Nature-nurture reconceptualized in developmental perspective: A bioecological model. Psychological Review, 101, 568586.

Brooks, P. J., Hanauer, J. B., Padowska, B., \& Rosman, H. (2003). The role of selective attention in preschoolers' rule use in a novel dimensional card sort. Cognitive Development, 18, 195-215.

Cairney, J., \& Streiner, D. L. (2011). Using relative improvement over chance (RIOC) to examine agreement between tests: Three case examples using studies of developmental coordination disorder (DCD) in children. Research in Developmental Disabilities, 32, 87-92.

Calkins, S. D., Blandon, A. Y., Williford, A. P., \& Keane, S. P. (2007). Biological, behavioral, and relational levels of resilience in the context of risk for early childhood behavior problems. Development and Psychopathology, 13, 255-276.

Cassidy, J. (1999). The nature of the child's ties. (p. 3.22). Handbook of attachment: Theory, research, and clinical applications, New York, NY: Guilford Press.

Cicchetti, D., \& Rogosch, F. (1996). Equifinality and multifinality in developmental psychopathology. Development and Psychopathology, 8, 597-600.

Colicis, O., Debuisson, M., Dussart, L., Mainguet, C., Vanden Dooren, L., \& Vander Stricht, V. (2004). Les communes les plus défavorisées sur le plan socioéconomique en Wallonie. Non published report from the Institut Wallon de l'Evaluation, de la Prospective et de la Statistique (IWEPS).

Copas, J. B., \& Loebert, R. (1990). Relative improvement over chance (RIOC) for $2 \times 2$ tables. British Journal of Mathematical and Statistical Analysis, 43, 293-307.

Deater-Deckard, K., Dodge, K. A., Bates, J. E., \& Pettit, G. S. (1998). Multiple risk factors in the development of externalizing behavior problems: Group and individual differences. Development and Psychopathology, 10, 469-493.

Diamond, A., \& Taylor, C. (1996). Development of an aspect of executive control: Development of the abilities to remember what I said and to Do as I say, not as I do. Developmental Psychobiology, 29(4), 315-334.

Dumas, J., LaFrenière, P., Capuano, F., \& Durning, P. (Eds.). (1997). Profil Socio-Affectif (PSA). Évaluation des compétences sociales et des difficultés d'adaptation des enfants de $2 \frac{1}{2}$ à 6 ans. Socio-affective profile: Rating of social competence and adaptive behavior of children aged 21/2 to 6 yearsParis: Éditions du Centre de Psychologie Appliquée.

Espy, K. A., Sheffield, T. D., Wiebe, S. A., Caron, A., \& Moehr, M. J. (2011). Executive control and dimensions of problem behaviors in preschool children. Journal of Child Psychology and Psychiatry, 52(1), 33-46.

Ezpeleta, L., Granero, R., de la Osa, N., \& Domènech, J. M. (2008). Risk factor clustering for psychopathology in socially at-risk Spanish children. Social Psychiatry and Psychiatric Epidemiology, 43, 559-568.

Fearon, R. P., Bakermans-Kranenburtg, M. J., Van Ijzendoorn, M. H., Lapsley, A.-M., \& Roisman, G. I. (2010). The significance of insecure attachment and disorganization in the development of children's externalizing behavior: A meta-analytic study. Child Development, 81(2), $435-456$.

Field, A. (2009). Discovering statistics using SPSS. London: Sage.

Flouri, E. (2008). Contextual risk and child psychopathology. Child Abuse and Neglect, 32, 913-917.

Floyd, F. J., \& Widaman, K. F. (1995). Factor analysis in the development and refinement of clinical assessment instruments. Psychological Assessment, 7(3), 286-299.

Furniss, T., Beyer, T., \& Müller, J. M. (2009). Impact of life events on child mental health before school entry at age six. European Child and Adolescent Psychiatry, 18, 717-724.

Gerard, J. M., \& Buehler, C. (2004). Cumulative environmental risk and youth problem behavior. Journal of Marriage and the Family, 66, $702-720$.

Gerstadt, C. L., Hong, Y. J., \& Diamond, A. (1994). The relationship between cognition and action: Performance of children 31/2-7 years old on a Stroop-like daynight test. Cognition, 53(2), 129-153.

Green, J., \& Goldwyn, R. (2002). Annotation: Attachment disorganization and psychopathology: New findings in attachment research and their potential implications for developmental psychopathology in childhood. Journal of Child Psychology and Psychiatry, 43(7), 835-846.

Green, J., Stanley, C., \& Peters, S. (2007). Disorganized attachment representation and atypical parenting in young school age children with externalizing disorder Attachment \& Human Development, 9(3), 207-222.

Greenberg, M. T., Speltz, M. L., DeKlyen, M., \& Jones, K. (2001). Correlates of clinical referral for early conduct problems: Variable- and person-oriented approaches. Development and Psychopathology, 13, 255-276.

Gusdorf, L. M. A., Karreman, A., van Aken, M. A. G., Dekovic, M., \& van Tuijl, C. (2011). The structure of effortful control in preschoolers and its relation to externalizing problems. British Journal of Developmental Psychology, 29(3), 612-634.

Hu, L., \& Bentler, P. M. (1999). Cutoff criteria for fit indexes in covariance structure analysis: Conventional criteria versus new alternatives. Structural Equation Modeling, 6, 1-55

Jang, S. J., \& Smith, C. A. (1997). A test of reciprocal causal relationships among parental supervision, affective ties, and delinquency. Journal of Research in Crime and Delinquency., 34, 307-336.

Janson, H., \& Mathiesen, K. S. (2008). Temperament profiles from infancy to middle childhood: Development and associations with behavior problems. Developmental Psychology, 44(5), 1314-1328.

Keller, T. E., Spieker, S. J., \& Gilchrist, L. (2005). Patterns of risk and trajectories of preschool problem behaviors: A person-oriented analysis of attachment in context. Development and Psychopathology, 17, 349-384.

Kemp, S., Kirk, U., \& Korkman, M. (2001). Essentials of NEPSY assessment. Hoboken, NJ, USA: John Wiley \& Sons Inc.

Kerr, M. A., Black, M. M., \& Krishnakumar, A. (2000). Failure-to-thrive, maltreatment and the behaviour and development of 6-year-old children from low-income, urban families: A cumulative risk model. Child Abuse and Neglect, 5(24), 587-598.

Kohnstamm, G. A., Halverson, C.F., Jr. Mervielde, I., \& Havill, V. (Eds.). (1998). Parental descriptions of child personality: Developmental antecedents of the big five. Mahwah, New Jersey: Lawrence Erlbaum Associates.

Lansford, J. E., Criss, M. M., Laird, R. D., Shaw, D. S., Pettit, G. S., Bates, J. E., et al. (2011). Reciprocal relations between parents' physical discipline and children's externalizing behavior during middle childhood and adolescence. Development and Psychopathology, 23, 225-238.

Lansford, J. E., Malone, P. S., Stevens, K. I., Dodge, K. A., Bates, J. E., \& Pettit, G. S. (2006). Developmental trajectories of externalizing and internalizing behaviors: Factors underlying resilience in physically abused children. Development and Psychopathology, 18(1), 35-55. 
Lanza, S. T., Rhoades, B. L., Nix, R. L., \& Greenberg, M. T. (2010). Modeling the interplay of multilevel risk factors for future academic and behavior problems: A person-centered approach. Development and Psychopathology, 22, 313-335.

Loeber, R., \& Farrington, D. P. (2000). Young children who commit crime: Epidemiology, developmental origins, risk factors, early interventions, and policy implications. Development and Psychopathology, 12, 737-762.

Lorenzi-Cioldi, F. (2003). Le questionnaire. In S. Moscovici \& F. Buschini (Eds.), Les méthodes des sciences humaines. The methods in human sciencesParis: PUF.

Marsh, A. A., \& Blair, R. J. R. (2008). Deficits in facial affect recognition among antisocial populations: A meta-analysis. Neurosciences E' Biobehavioral Reviews, 32(3), 454-465.

Martel, M. M., \& Nigg, J. T. (2006). Child ADHD and personality/temperament traits of reactive and effortful control, resiliency, and emotionality. Journal of Child Psychology and Psychiatry, 47(11), 1175-1183.

Masten, A., Roisman, G. I., Long, J. D., Burt, K. B., Obradovic, J., Riley, J. R., et al. (2005). Developmental cascades: Linking academic achievement and externalizing and internalizing symptoms over 20 years. Developmental Psychology, 41(5), 733-746.

Mervielde, I., De Clercq, B., De Fruyt, F., \& Van Leeuwen, K. (2005). Temperament, personality, and developmental psychopathology as childhood antecedents of personality disorders. Journal of Personality Disorders, 19(2), 171-201.

Meunier, J. C., \& Roskam, I. (2009). Validation of the preschool and primary school form of a questionnaire assessing parents' childrearing behaviour. Journal of Clinical Child and Adolescent Psychology, 38(1), 166-175.

Meunier, J. C., Roskam, I., \& Browne, D. T. (2011). Relations between parenting and child's problem behaviour. Exploring child's personality and parental selfefficacy as third variables. International Journal of Behavioral Development, 35(3), 246-259.

Meunier, J. C., Roskam, I., Stievenart, M., van de Moortele, G., Browne, D. T., \& Kumar, A. (2011). Externalizing behavior trajectories: The role of parenting, sibling relationships and child personality. Journal of Applied Developmental Psychology, 32(1), 20-33.

Miljkovitch, R., Pierrehumbert, B., Karmaniola, A., \& Halfon, O. (2003). Les représentations d'attachement du jeune enfant. Développement d'un système de codage pour les histoires à compléter [[Representations of attachment in the young child. Development of a coding system for stories to be completed]. Devenir, 15(2), $143-177$.

Nigg, J. T., Quamma, J. P., Greenberg, M. T., \& Kusche, C. A. (1999). A two-year longitudinal study of neuropsychological and cognitive performance in relation to behavioral problems and competencies in elementary school children. Journal of Abnormal Child Psychology, 27(1), 51-63.

Oakes, J. M., \& Rossi, P. H. (2003). The measurement of SES in health research: Current practice and steps toward a new approach. Social Science \& Medicine, 26, 769-784.

Peterson, R. A. (2000). Constructing effective questionnaire. London: Sage.

Pierrehumbert, B., Santelices, M. P., Ibáñez, M., Alberdi, M., Ongari, B., Roskam, I., et al. (2009). Gender and attachment representations in the preschool years: Comparisons between five countries. Journal of Cross-Cultural Psychology, 40(4), 543-566.

Reader, M. J., Harris, E. L., Schuerholz, L. J., \& Denckla, M. B. (1994). Attention deficit hyperactivity disorder and executive dysfunction. Developmental Neuropsychology, 10, 493-512.

Rhoades, B. L., Greenberg, M. T., \& Domitrovich, C. E. (2009). The contribution of inhibitory control to preschoolers' social-emotional competence. Journal of Applied Developmental Psychology, 30(3), 310-320.

Roskam, I., de Maere-Gaudissart, A., \& Vandenplas-Holper, C. (2000). Mise au point d'un instrument d'évaluation de la personnalité des enfants à partir du Modèle à Cinq Facteurs [[Validation of bipolar rating scales based on the Five-Factor Model of personality]. L'Orientation Scolaire et Professionnelle, 29(4), 661-672.

Rothbart, M. K., \& Bates, J. E. (1998). Temperament. Hoboken, NJ, US, John Wiley \& Sons Inc, Hoboken, NJ.

Rouse, H. L., Fantuzzo, J. W., \& Leboeuf, W. (2011). Comprehensive challenges for the well being of young children: A population-based study of publicy monitored risks in a large urban center. Child Youth Care Forum, 40, 281-302.

Rueter, M. A., \& Conger, R. D. (1998). Reciprocal influences between parenting and adolescent problem-solving behavior. Developmental Psychology, 34, 14701482.

Sameroff, A. J., Seifer, R., \& McDonough, S. C. (2004). Contextual contributors to the assessment of infant mental health. In R. DelCarmen-Wiggins \& A. Carter (Eds.), Handbook of infant, toddler, and preschool mental health assessment. Oxford University Press: New York.

Scarr, S., \& McCartney, K. (1983). How people make their own environments: A theory of genotype-environment effects. Child Development, 54, 424-435.

Schonberg, M. A., \& Shaw, D. S. (2007). Do the predictors of child conduct problems vary by high- to low-levels of socioeconomic and neighborhood risk? Clinical Child and Family Psychology Review, 10(2), 101-136.

Shaffer, D. R. (2009). Social and personality development (6th edition). Belmont: Wadsworth, Cengage Learning.

Smeekens, S., Risken-Walraven, J. M., \& Van Bakel, H. J. A. (2009). The predictive value of different infant attachment measures for socioemotional development at age 5 years. Infant Mental Health Journal, 30(4), 366-383.

Stacks, A. M. (2007). Defensive dysregulation in preschool children's attachment story narratives and its relation to attachment classification and externalizing behaviour. School Psychology International, 28(3), 294-312.

Stievenart, M., Roskam, I., Meunier, J-C., \& Van de Moortele, G. (2010). The reciprocal relationship between children's attachment representations and their cognitive ability. International Journal of Behavioral Development, 35(1), 58-66.

Trentacosta, C. J., Hyde, L. W., Shaw, D. S., Dishion, T. J., Gardner, F., \& Wilson, M. (2008). The relations among cumulative risk, parenting, and behaviour problems during early childhood. Journal of Child Psychology and Psychiatry, 49(11), 1211-1219.

Van Ijzendoorn, M., Schuengel, C., \& Bakermans-Kranenburg, M. (1999). Disorganized attachment in early childhood: Meta-analysis of precursors, concomitants, and sequelae. Development and Psychopathology, 11, 225-250.

Van Schendel, C., Schelstraete, M-A., \& Roskam, I. (in press). Développement langagier de l'enfant d'âge pré scolaire présentant des troubles externalisés du comportement: une revue de littérature [Language development in preschoolers displaying externalizing behavior. A litterature review]. L'Année Psychologique.

Wakschlag, L. S., Briggs-Gowan, M. J., Carter, A. S., Hill, C., Danis, B., Keenan, K., et al. (2007). A developmental framework for distinguishing disruptive behavior from normative misbehavior in preschool children. Journal of Child Psychology and Psychiatry, 48(10), $976-987$.

Wechsler, D. (Ed.). (2004). WPPSI-III: Manuel d'interprétation. Paris: Les Editions du Centre de Psychologie Appliquée. 